\title{
Endoscopic Management of Foreign Body Nose Removal with Self Fabricated Blunt Hooks: An Experience of 1156 Cases
}

\author{
Ranga $\mathrm{RK}^{1 *}$ and Yadav SPS ${ }^{2}$ \\ ${ }^{1}$ Director, Bharat ENT \& Endoscopy Hospital, India \\ ${ }^{2}$ Department of Otorhinolaryngology, Pt.BD Sharma Medical University, India
}

*Corresponding author: Rupender K Ranga, Director, Bharat ENT \& Endoscopy Hospital, Rohtak Gate- Bhiwani-127021, Haryana, India, Tel: +919416059402; Email: rupenderent@ yahoo.co.in

\section{Research Article \\ Volume 6 Issue 1}

Received Date: March 18, 2021

Published Date: April 05, 2021

DOI: $10.23880 /$ ooaj-16000210

\section{Abstract}

Nasal foreign bodies is common pediatric emergency in otorhinolaryngology. Sometimes these may get dislodged in the airways which may prove catastrophic.

Aim: To analyzed the age, sex, side of nose, nature of foreign bodies and complications in pediatric population in India.

Material \& Methods: 1156 cases of nasal foreign bodies removed endoscopically in age group of 1-14 years in the years 2001 to 2014 were evaluated according to the parameter related above. Two self-fabricated simple and atraumatic nasal foreign body hooks were used for removal of foreign bodies.

Results: We observed higher incidence of foreign bodies in 1-4 years age group, inorganic foreign bodies (601) being more common than organic foreign bodies (555). Minor complications like momentary nasal bleeding due to laceration of nasal mucosa were observed in very few cases.

Conclusion: Nasal endoscopy is best technique for removal of foreign bodies which is very quick, safe, less traumatic and site is well visualized. Foreign body hooks used by us are economical and atraumatic. Any Otorhinolaryngologist can make these hooks in his/ her clinic.

Keywords: Nasal foreign bodies, Nasopharynx; Oropharynx; Laryngopharynx

\section{Introduction}

Foreign body nose is common rhinological emergency encountered in our daily practice. Although these are frequent in pediatric population, however, can occasionally be seen in adults especially in mentally challenged [1]. The first year of child's life represent a phase of exploration and interaction with environment, when they start moving by their own means (crawling and walking), the child starts having access to number of objects which they duly explore
[2]. The vast majority of foreign bodies are placed in the nose voluntarily for endless variety of reasons, more so due to easy availability of objects and absence of watchful caretaker. Any foreign body stuck in the nose has the potential to dislodge and travel into nasopharynx, oropharynx, laryngopharynx and occasionally in tracheobronchial tree [3].

Foreign bodies can be classified as organic and inorganic. Organic foreign bodies include food, rubber, wood, sponge and metallic batteries, which causes more irritation to 
nasal mucosa and produce earlier symptoms. Inorganic foreign bodies include plastic or metals e.g. beads, button, stones, paper and small parts of toys [4]. These remain often asymptomatic and may be discovered incidentally. We share our experience of 1156 foreign bodies removal from nose.

\section{Material and Methods}

The present retrospective hospital based study included 1156 pediatric patients of either sex in age group of 1-14 years with foreign bodies in nose during 2001 to 2014 . Common presentation included history of foreign body insertion into nose observed by parents, nasal obstruction, epistaxis, pain and foul smelling nasal discharge usually unilateral. ENT examination was carried out in each patient. Anterior rhinoscopy revealed most of the foreign bodies. However, in some suspected cases X-ray PNS OM view and $\mathrm{X}$-ray nasopharynx lateral view were obtained. Preoperative routine investigation like $\mathrm{Hb}, \mathrm{BT}, \mathrm{CT}$ and complete urine examination was done in cases where general anesthesia was required. In all patients written informed consent was obtained for nasal endoscopy.

In majority of patients' foreign bodies were removed under local anesthesia. Premedication in the form syrup promethazine $5-10 \mathrm{ml}$ was given depending on weight of patient and 4\% lignocaine with xylometazoline $0.05 \%$, locally instilled into both nostrils for about 10-15 minutes prior to procedure. Patients were made to lie down in supine position with head end elevated $10^{\circ}$ to $15^{\circ}$ to reduce the venous pressure. Head, arms and legs were secured with straps by the assistant for better stabilization. Hopkin's rigid pediatric endoscope $(2.7 \mathrm{~mm} 0$ degree $)$ was introduced and foreign bodies were visualized and removed with hook which was passed over the foreign body and lowered up to floor and the foreign body was removed.

Instruments (foreign body hook)
1. The foreign body hook (Dr. Ranga's F.B. Hook) was fabricated from a used nasal perichondrium elevator. The end was filled to make it more blunt and non-traumatic, and was bent $60^{\circ}$ (Figure 1).

2. Dr. Yadav's foreign body hook was fabricated from Eustachian tube catheter. First the blunt catheter was straightened and then the tip (5-6 mm) was bent $90^{\circ}$ to make it like a hook (Figure 2). Both these instruments are non-traumatic as the ends were blunt and very easy to insert in infant and child's nasal cavity which is very small. Further suction tube can be attached to facilitate removal.

The flat foreign bodies like paper were removed by baynet forceps under endoscopic vision. After removal of foreign body re-examination of both nostrils was carried out to exclude any part of foreign body or any other foreign body. Postoperatively syrup co-amoxiclav 5ml BID, syrup ibuprofen $5 \mathrm{ml}$ TID and normal saline local instillation 3 drops TID was given. All patients were discharged on same day. On follow up after 7-10 days no complaint was reported by patients. Those children who were not cooperative or there was failure of foreign body removal due to impaction or had previous unsuccessful attempts were removed under general anesthesia. Data regarding age, sex, side of nose, duration and types of foreign body were analyzed.

\section{Results}

A total number of 1156 foreign bodies patients were included in the study, which was divided in subgroups agewise e.g. 1 -4 years 672 patients (58.13\%), 402 (59.8\%) males and $270(40.2 \%)$ females. Age group 5-8 years included 336 (29.06\%) patients, 198 (58.9\%) males, 138 (41.07\%) females. Age group 9-12 years were 129 (11.15\%) patients, 92 (71.31\%) males and 37 (28.68\%) females. In age group of $>12$ years there were $19(2.5 \%)$ patients 11 being $(57.5 \%)$ males and 08 (42.1\%) females (Table 1, Figures $1 \& 2$ ).

\begin{tabular}{|c|c|c|c|c|}
\hline Sr. No. & Age groups in years & Number (\%) & Males (\%) & Females (\%) \\
\hline 1 & $1-4$ & $672(58.13 \%)$ & $402(59.8 \%)$ & $270(40.2 \%)$ \\
\hline 2 & $5-8$ & $336(29.06 \%)$ & $198(58.9 \%)$ & $138(41.07 \%)$ \\
\hline 3 & $9-12$ & $129(11.15 \%)$ & $92(71.31 \%)$ & $37(28.68 \%)$ \\
\hline 4 & $>12$ & $19(2.5 \%)$ & $11(57.5 \%)$ & $08(42.1 \%)$ \\
\hline Total & & 1156 & 703 & 453 \\
\hline
\end{tabular}

Table 1: Age \& Sex distribution of Foreign bodies in children. 

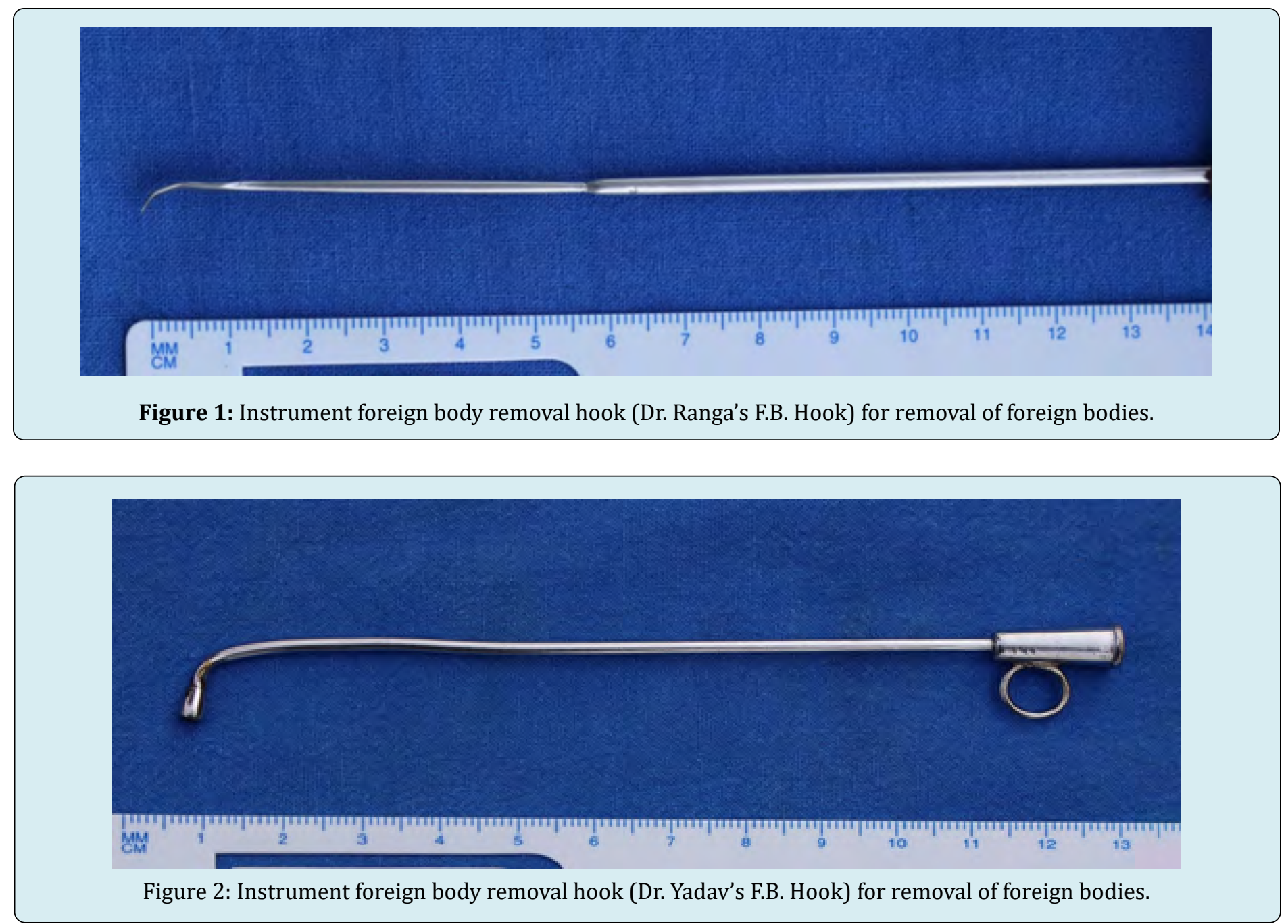

There were 555 (48\%) organic foreign bodies (Figure 3) which included groundnut $54(10 \%)$, parched gram $38(7 \%)$, berry $26(5 \%)$, green pea $26(5 \%)$, split gram $25(5 \%)$, piece of eraser $24(4 \%)$, chicklet $23(4 \%)$, cotton seed $22(4 \%)$, cotton $20(4 \%)$, sponge $19(3 \%)$, tamarind seed $18(3 \%)$, popcorn $18(3 \%)$, toffee $17(3 \%)$, seed of berry $17(3 \%)$, Cadbury gem $16(3 \%)$, sev bhujia $16(3 \%)$, acacia seed 15 (3\%), fox nut $14(3 \%)$, small cell batteries $13(2 \%)$, pumpkin seed $13(2 \%)$, piece of acacia fruit $12(2 \%)$, bitternut 12 (2\%), wall nut $12(2 \%)$, corn kernel $12(2 \%)$, almond 10 (2\%), piece of wood $10(2 \%)$, cashew nut $9(2 \%)$, button cell batteries $8(1 \%)$, piece of lead pencil $8(1 \%)$ and resin $6(1 \%)$.

There were 601 (52\%) inorganic foreign bodies (Figure
4) which included bead $50(8 \%)$, plastic button $43(7 \%)$, thermacol ball $30(5 \%)$, metallic button $26(4 \%)$, ball pen endcap $30(5 \%)$, ball pen forecap $25(4 \%)$, sketch pen endcap $24(4 \%)$, small metallic bell $21(3 \%)$, piece of toy $19(3 \%)$, stone $18(3 \%)$, piece of slate pencil $18(3 \%)$, wax colour $18(3 \%)$, standard biconvex tablet $18(3 \%)$, plastic whistle $18(3 \%)$, piece of paper $17(3 \%)$, bindi (forehead dots) 17 (3\%), marble $16(3 \%)$, modified rectangular tablet $16(3 \%)$, diwali light bulb $15(2 \%)$, nose pin $15(2 \%)$, chalk piece 13 (2\%), bangle piece $13(2 \%)$, Hajmola goli $12(2 \%)$, hingoli $12(2 \%)$, nail $12(2 \%)$, spent medium bullet $12(2 \%)$, small spent bullet $11(2 \%)$, metallic nut $11(2 \%)$, locking safety pin $10(2 \%)$, piece of remote button $10(2 \%)$, piece of cracker 9 $(1 \%)$, screw $8(1 \%)$, piece of match stick $8(1 \%)$ and sea shell $6(1 \%)$ (Figure 5). 


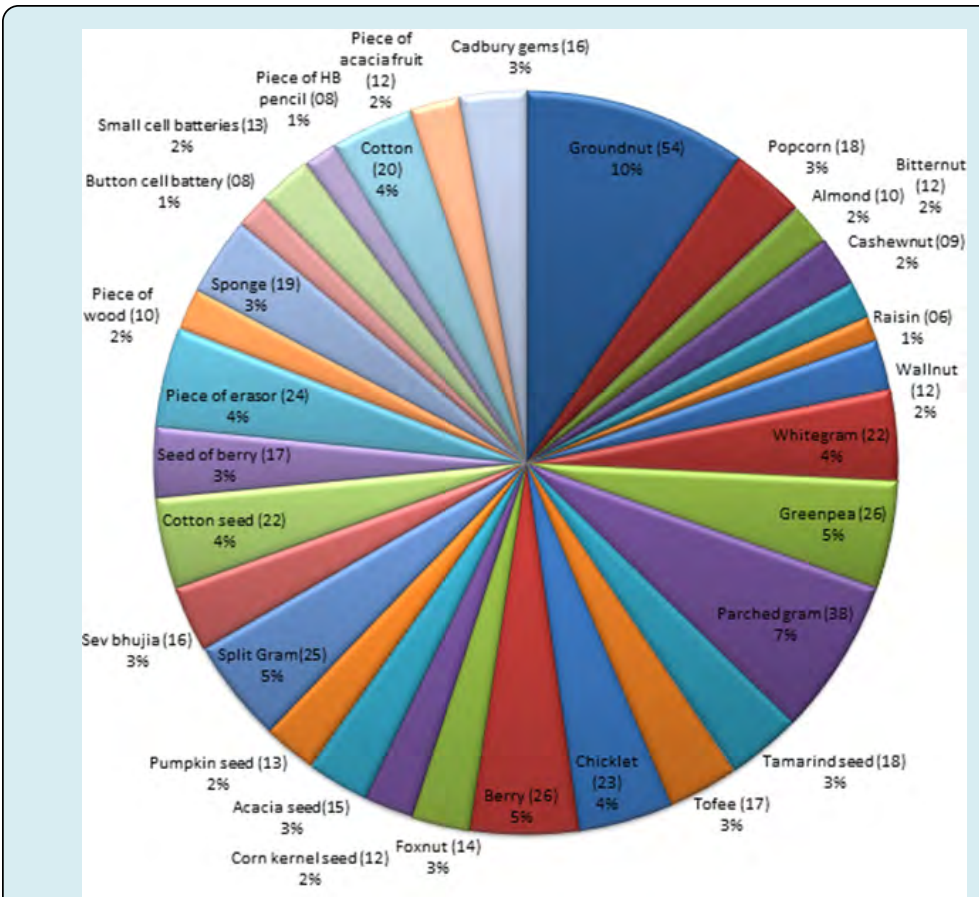

Figure 3: Organic foreign bodies in nose $(n=555)$.

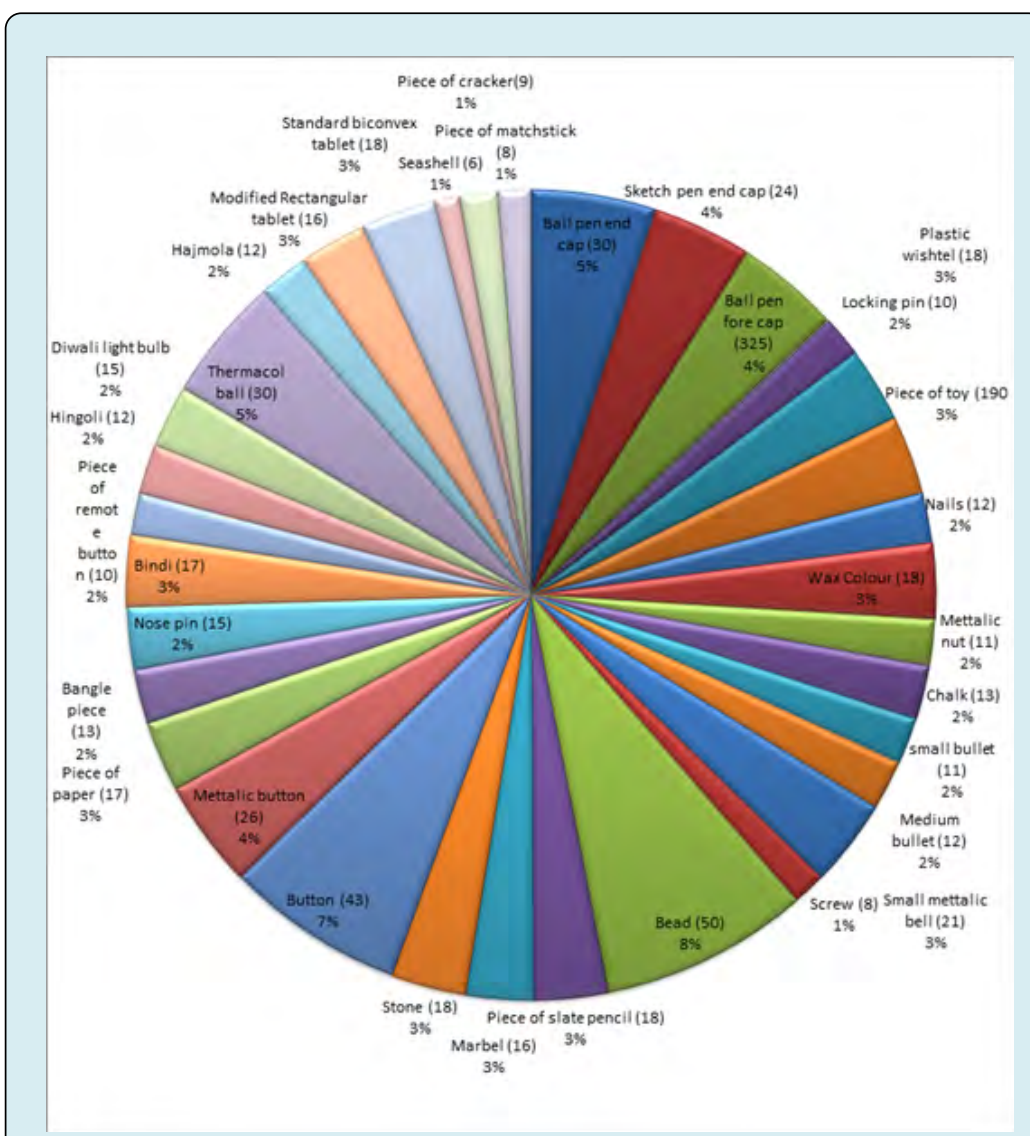

Figure 4: Inorganic foreign bodies in nose $(\mathrm{n}=601)$. 


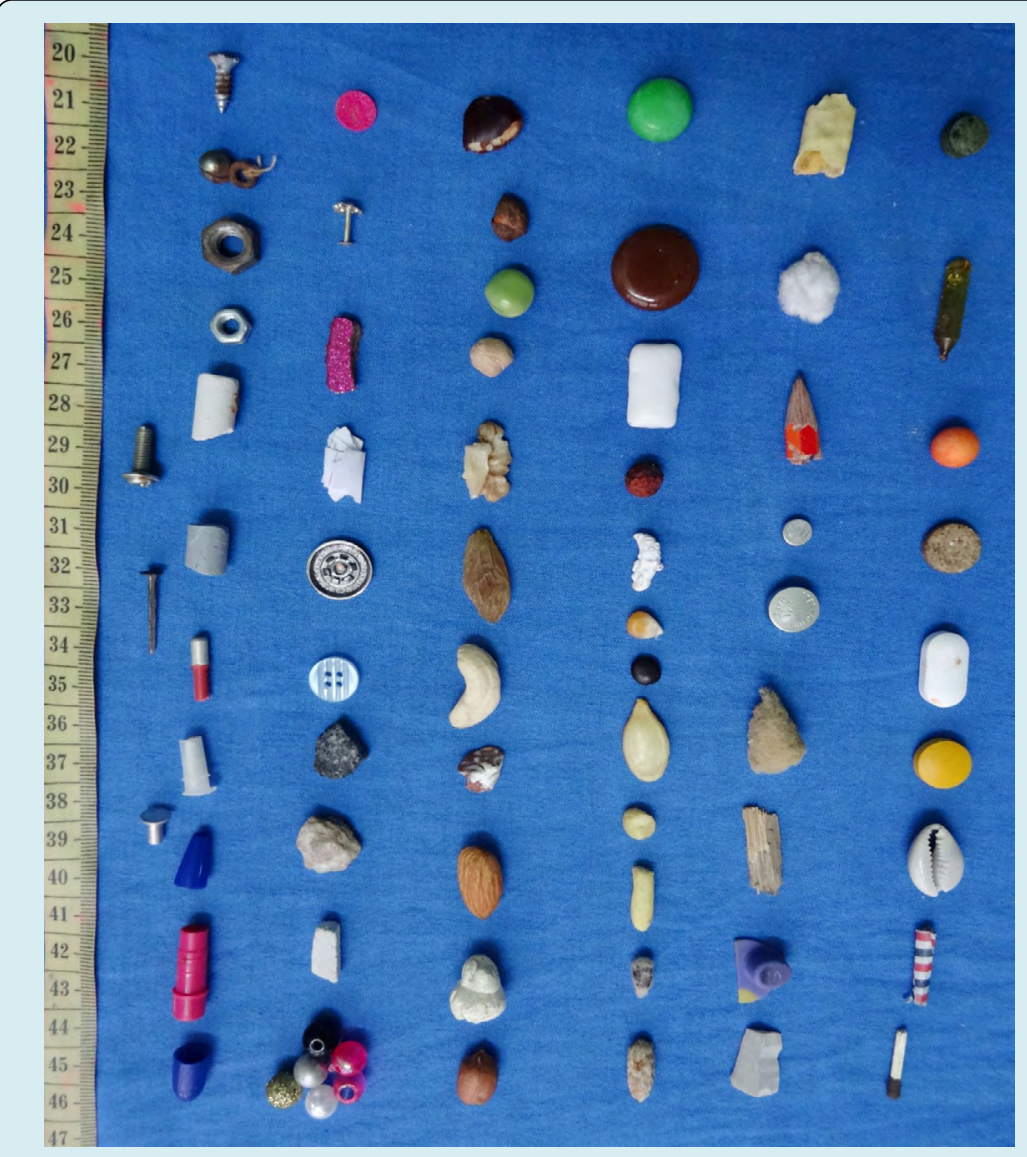

Figure 5: Different types of foreign bodies.

Foreign bodies were in right side of nose in 770 (66.6\%), left nostril in 385 (33.3\%) cases and in one case these were bilateral. Duration of lodgment comprised 1-2 days in 1108 patients whereas 7-10 day in 46 cases and mean duration was \pm 2.6 days. Only in two cases foreign bodies dislodged posteriorly and coughed out.

\section{Discussion}

The foreign bodies theme is concern to our whole society and everybody should know that it can lead onto severe complications and occasionally even death. Foreign bodies are usually lodged in the anterior or middle third of the nasal cavity between septum and inferior or middle turbinate [5]. Successful removing a foreign body nose depends on a number of factors like size, shape, texture, time or duration of foreign body lodgment, cooperation of child at the time of removal, visualization of foreign body and surrounding structure trauma to nasal cavity due to insertion or removal attempts of foreign body and skill of the otolaryngologist $[1,4]$. The first attempt is likely to be the most successful as repeated tries not only cause future swelling and bleeding which definitely compromise the patient cooperation [2].
These must be removed under general anesthesia.

In our study most common age groups was 1-4 years with 672 foreign bodies (58.13\%) and decreased inversely with increase in the age, which is comparable to earlier studies with relation to age. It is due to fact that around the age of 9 months when a child develops the pincer grip which allows easy manipulation of small objects. Curious children may insert small objects into their nose in normal attempts to explore their own bodies [6-8]. In age group 5-8, 9-12 \& > 12 years cases were lower due to more awareness at the part of children as well as their parents. There was predilection of foreign bodies in the right nostril $770(66.6 \%)$ than left nostril $385(33.4 \%)$. It may be due to the fact that majority of population being right handed hence their right nostril is nearer than left and easy to access to insert the foreign body as also reported earlier [5]. At the place of study, there is definite preponderance of right handedness in general population. Males were affected more than females which is comparable with earlier investigators $[1,6,9]$.

Most common types of foreign bodies in nose being inorganic $52 \%$ as compared to organic foreign bodies $48 \%$, however, foreign body lodgment depends upon the region 


\section{Otolaryngology Open Access Journal}

wise availability and usage of articles in day to day life. The common foreign bodies were groundnuts. It is commonly eaten in winter season which is easily accessible to children for eating and sometimes insertion in the nose. Parched grain, split gram, popcorn, toffee, Cadburys gem, sev bhujia, fox nut, wall nut, corn kernel, almond, cashew nut, resin and chicklet are common curious \& tasteful food items used to feed and pacify the children at the place of study. Insertion of foreign bodies may be due to boredom, frustration and unhealthy nose picking habits [10]. Different types of seeds such as green pea, acacia, cotton, berry, pumpkin, bitternut and tamarind which are also very commonly lying in houses. Cotton and sponges fragments are being usually removed from pillow and damaged mattress are also easily available. Berry and piece of acacia fruit are present in abundance in tropical climate as at the place of study. Common primary stationary such as eraser, lead \& slate pencils and chalk are used in primary elementary education. Organic foreign bodies tend to swell, hence are usually more symptomatic than inorganic [11].

Pencil or pen batteries as well as button cell batteries are used extensively in many devices like hearing aids, electronic games, watches, digital planners and new electronic toys. Their smooth and shiny appearance makes them quite attractive and interesting to children who eagerly handle them when they are accessible. The clinical course of batteries depends upon several factors including location, duration, mucosal contact, remaining electric voltage in battery and chemical composition [12]. In our study we did not observe any septal ulceration or perforation and necrosis of inferior turbinates. It is due to fact that duration of insertion and removal of batteries was less than six hours in all our cases, however, liquefaction necrosis of nasal mucosa due to leakage of alkaline electrolyte solution and residual electrical voltage in batteries has been reported earlier [13].

Most commonly encountered inorganic foreign bodies are beads and buttons which are used for shirts and decoration of clothes. In last few decades increasing demands of stationary material by children in the form of ball pen, sketch pen, papers and chalks has also lead onto increase in the incidence of foreign bodies in nose [11]. It is natural habit of children to play with toys like plastic whistle, remote control and seashell and sometime care taker is not looking after the children, and they get opportunity to insert into nasal orifice [1]. These days in the most of houses either parents or children are taking treatments in the form of tablets in various shape and size, children may play with these and sometime insert in to their nostril as was also observed in the present study. Bindi (forehead dots), bangles, nose pin and locking pins are used by Indian females for mak and routine accessories which are in easy reach of child cc as was observed by us. Furnitures and kitchen wares in the houses have nail, screw, nut and bolt which get loose with passage of time. Curious children play with them when these get detached from the site of placement and inserted into nasal cavity. In contrast to organic foreign bodies inorganic foreign bodies have high rate of successful removal [14].

Marble chips are used in making floors and for decoration in drawing room at the place of study. Marble especially coloured marble looks attractive to children and they get curious to explore it's nature and accidently insert into their noses [15]. In India Diwali is a festival of lights where lots of decorations with different colored lights are used. The children have natural attraction to these, they play with them and insert pieces of light in noses. Remnants of used cracker which are lying either at home or in playground, children can insert in the nose. Match sticks are commonly used in our daily life and used match sticks are lying at the place where children play. Children play with them and can put either in oral or nasal cavity.

Pediatric nasal endoscopy is the best method for diagnosis and removal of foreign bodies [16,17]. Removal of foreign bodies with nasal endoscope is very quick, safe, less traumatic and visualize the site of lodgment of foreign bodies in nose with least morbidity. We have also observed that under the age of 4 years child's size of nasal cavity is smaller and removal of foreign bodies is difficult and challenging and require general anesthesia, however, we have removed mostly under local anesthesia. In our study most of the foreign bodies were located in the anterior part of nasal cavity. Children between 1-12 years are afraid of doctor and instruments, it is better to hold arms \& legs for proper stabilization and easy visualization of foreign bodies. General anesthesia is given to apprehensive children. We have removed all foreign bodies using nasal hooks designed by us except foreign bodies like paper etc. It is important to pass the tip of instrument over and beyond the foreign body under endoscopic guidance in the nose, hooked and drawn along the floor of nasal cavity. In our study we have minor complications like epistaxis and lacerations of nasal mucosa in 26 cases.

However, one must not forget the golden rule that first attempt has the best chance of removal of foreign body nose. As the child becomes afraid, then they usually don't cooperate. So don't attempt twice under local anesthesia, second attempt and in overtly apprehensive children even the first attempt should always be under general anesthesia Endoscopy management is definitely preferable.

\section{Conclusion}

Self-Fabricated Blunt Hooks, convenient and atraumatic for removal of nasal foreign bodies without any complications. 


\section{Otolaryngology Open Access Journal}

\section{References}

1. Hafeez M, Inayatullah Z (2009) Foreign body nose in children: A common problem with social roots. Abasyn Uni J Social Sci 2(1): 22-25.

2. Davis PH, Benzer JR (2000) Foreign bodies in the nose and ear: A review of techniques for removal in emergency department. J Accid Emerg Med 17(2): 91-94.

3. Heim SW, Maughan KL (2007) Foreign bodies in ear, nose and throat. Am Fam Physician 76(8): 1185- 1189.

4. Ngo A, Ng KC, Sim TP (2005) Otorhinolaryngeal foreign bodies in children presenting to the emergency department. Singapore Med J 46(4): 172-178.

5. Figueiredo RR, Azevedo AA, Kos AO, Tomita S (2006) Nasal foreign bodies: Description of types and complication in 420 cases. Rev Bras Otorhinolaryngol 72(1): 18-23.

6. Shrestha I, Shrestha BL, Amatya RCM (2012) Analysis of ear, nose and throat foreign bodies in Dhulikhel Hospital. Kathmandu Uni Med J 10(38): 4-8.

7. Harner SG (1975) Foreign bodies in ear, nose and throat. Postgrad Med J 57(6): 82-83.

8. Baker MD (1987) Foreign bodies of ear and nose in childhood. Pediatr Emerg Care 3(2): 67-70.

9. Purohit N, Bay S, Wilson T, Chawla OP (2008) The parent's kiss: An effective way to remove pediatric nasal foreign bodies. Ann R Coll Surg Engl 90(5): 420-422.

10. Mukherjee A, Haldar D, Dutta S, Dutta M, Saha J, et al. (2011) Ear, nose and throat foreign bodies in children: A search for socio- demographic correlation. Int J Pediatr Otorhinolaryngol 75(4): 510-512.

11. Hafeez M, Zakirullah M, Inayatullah M (2011) Foreign body nose in children presenting at a tertiary care teaching hospital in Pakistan. Pak J Med Sci 27(1): 124-127.

12. Majumdar AB, Sengupta A, Paul SS (2014) A case series of button batteries as nasal foreign bodies among children. Int J Adv Med 1(3): 273-276.

13. Bhatia R, Singhal S, Das A (2010) Button cell causing septal perforation in a child: case report. Clin Rhinol Int J 3(3): 161-163.

14. Schulze SL, Kerschner J, Beste D (2002) Pediatric foreign bodies: A review of 678 cases. Otolaryngol Head Neck Surg 127: 73-78.

15. Kalan A, Tariq M (2000) Foreign bodies in the nasal cavities: A comprehensive review of the aetiology, diagnostic pointer and therapeutic measure. Postgrad Med J 76(898): 484-487.

16. Giourgor G, Matti E, Pagella F (2009) Endoscopic removal of nasal foreign body with hook-scope technique. Eur Arch Otorhinolaryngol 266(10): 1663-1665.

17. Ranga RK, Yadav SPS, Singh J, Singh I (2011) Mutton in nasopharynx in a toddler. Clin Rhinol Int J 4(2): 105-106. 